\section{Leprosy persistence in the health district of Kenieba despite its \\ elimination as a public health problem at the national level in Mali} \author{
and Samba Ousmane Sow ${ }^{1}$ \\ ${ }^{1}$ Centre National d'Appui à la lutte contre la Maladie, Mali \\ ${ }^{2}$ International Center for Excellence in Research, Mali \\ ${ }^{3}$ Centre de Santé de Référence de Kenieba, Mali \\ ${ }^{4}$ Faculty of Medicine and Dentistry, Bamako, Mali \\ ${ }^{5}$ Programme National de Lutte contre la Lèpre, Mali
}

Yaya Ibrahim Coulibaly1,2, Ilo Dicko ${ }^{2 *}$, Modibo Keita', Housseini Dolo ${ }^{2}$, Modibo Sangaré4, Abdoulaye Fomba', Mamoudou Kodio', Nouhou Diarra ${ }^{3}$, Mamadou Sidibé ${ }^{5}$, Oumar Maiga ${ }^{1}$, Moussa Brema Sangaré 2 , Siaka Yamoussa Coulibaly², Michel Emmanuel Coulibaly ${ }^{2}$, Mamadou Dolo이 ${ }^{2}$, Sory Ibrahima Fomba ${ }^{2}$, Abdallah Amadou Diallo², Floribert Fossuo Thotchum², Ousmane Faye ${ }^{1}$

\section{Abstract}

WHO defined leprosy elimination as reaching a prevalence $<1$ case of leprosy per 10,000 inhabitants. Mali eliminated the disease since 2001 but in 2011, it recorded 226 new cases. This has a serious involvement in term of disease spreading. Therefore, we undertook a cross sectional study in Kenieba health district, still above the WHO recommended elimination threshold to better understand the disease epidemiology and its associated potential factors. The study took place from October 2013 to September 2014. All consenting villagers, living in one of the selected villages were included and clinically examined for leprosy signs.

A total of 8,457 participants were included in this cross-sectional survey. The median age was 14 varying 0 to 102 years. The sex ratio was equal to 0.92 . Nine new leprosy cases corresponding to a new case detection rate of 10.64 per 10,000 population were diagnosed. Four of them were multibacillary leprosy and three were found positive to acid-fast bacilli. The estimated prevalence of leprosy was 24.83 per 10,000 population. Living in Kenieba city $(R R=0.97, \mathrm{Cl}=[0.95-0.99])$, using a bicycle $(R R=0.96, \mathrm{Cl}=[0.93-0.99])$ or other vehicle as transportation mean to reach the health center $(\mathrm{RR}=0.96, \mathrm{Cl}=[0.93-0.99])$ were protective factors significantly associated with new leprosy cases. Other factors such as age, education status, gender, time to reach a health center were not associated with leprosy case. Six among the nine health workers questioned knew at least two clinical signs of leprosy, three, its therapeutic regimens and three claimed to have previously being trained in diagnosing the disease.

Despite leprosy elimination as a public health problem at the country level, it remains highly endemic in the health district of Kenieba.

\section{More Information}

*Address for Correspondence: Ilo Dicko, International Center for Excellence in Research, Mali (ICER-Mali), Faculty of medicine and dentistry, Bamako, University of Sciences, Techniques and Technologies of Bamako (USTTB), Mali, Post box: 1805,

Tel: + (223) 76041491; Email: ilo@icermali.org

Submitted: 08 November 2019

Approved: 20 February 2020

Published: 21 February 2020

How to cite this article: Coulibaly YI, Dicko I, Keita M, Dolo H, Sangaré M, et al. Leprosy persistence in the health district of Kenieba despite its elimination as a public health problem at the national level in Mali. Ann Dermatol Res. 2020; 4: 001-005.

\section{DOI: dx.doi.org/10.29328/journal.adr.1001009}

Copyright: @ 2020 Coulibaly YI, et al. This is an open access article distributed under the Creative Commons Attribution License, which permits unrestricted use, distribution, and reproduction in any medium, provided the original work is properly cited.

Keywords: Leprosy; New cases; Active detection; Relative risk; Kenieba; Mali

\section{Check for updates}

OPEN ACCESS

\section{Introduction}

Neglected tropical diseases (NTDs) are a disabling and disfiguring group of diseases that affect the most vulnerable and the poor populations worldwide [1,2]. Leprosy, an NTD caused by Mycobacterium leprae (M. leprae) [3], primarily affects the skin and peripheral nerves, resulting in sensory loss [4]. Transmission occurs primarily through the nasal mucosa, but recent research indicates that the bacilli are also present in the mouth [5].

In late 2018, the World Health Organization (WHO) 
reported a global leprosy prevalence of 0.24 per 10,000 population [6]. Worldwide, the number of reported new leprosy cases decreased from 244,796 in 2009 to 208,619 in 2018. Except in South-East Asia, all the other WHO regions reported more new leprosy cases in 2018 than in 2017 [6].

The WHO defines leprosy elimination as a prevalence of less than 1 case of leprosy per 10,000 population [7]. Currently, access to information, diagnosis and treatment with multidrug therapy (MDT) constitute the key elements in the strategy to eliminate leprosy as a public health problem. Since 1995, WHO has made MDT, with the simple and highly effective combination of rifampicin, clofazamine and dapsone available for free in endemic areas and recommends early leprosy diagnosis and treatment to prevent disabilities [6].

Mali achieved leprosy elimination in 2001 (unpublished data from the National Leprosy Control Program). However, Kenieba health district in 2011 had a prevalence equal to 1.2 per 10,000 population (unpublished data from the National Leprosy Control Program). At the same time, 226 new leprosy cases were detected country-wide (annual report of the National Leprosy Control Program). This has serious implications in terms of disease spread. Therefore, we undertook a cross sectional study aiming to actively search leprosy cases and determine their associated factors in Kenieba health district, region of Kayes, Mali.

\section{Materials and methods}

\section{Study design}

We undertook a prospective cross-sectional study from October 2013 to September 2014.

\section{Study site}

The health district of Kenieba is located in the southern part of the administrative region of Kayes. It covers 16,800 $\mathrm{km}^{2}$ and extends over $125 \mathrm{~km}$ from North to South and $195 \mathrm{~km}$ from East to West. With a hilly landscape, it is comprised of a vast plain and mountains that reach over 100 meters in height. Kenieba belongs to Sudanese climatic zone. It experiences a long dry season from November to June when temperatures reach $25^{\circ} \mathrm{C}$ at night and $47^{\circ} \mathrm{C}$ during the day. The dry season is followed by a wet season extending from July to September, during which population movements become very difficult due to flooding [8].

\section{Malian health system organization}

The Malian health system is organized in 3 administrative levels: central (national level), regional (administrative region level) and operational (health district level). The central level organizes and directs the system and gives recommendations to the 8 regional levels. The regional health directorates are each responsible for several health districts called CSRéf. Each CSRéf is also responsible for a various number of community health centers (CSCOM). Every CSCOM covers in its turn some health areas represented by 5 to 25 villages (each populated with at least 3,000 inhabitants) to which it provides with a package of curative, preventive and promotional health services [9].

\section{Study village selection}

Kenieba health district is composed of 22 CSCOM; it is characterized by a lack of medical doctors as compared to WHO recommendations (1 medical doctor per 10,000 inhabitants) $[10,11]$. We conducted our study in 20 villages from 5 CSCOM of Kenieba health district in the region of Kayes, Mali. The study villages were selected in a convenient way during a meeting between the research team and the Chief medical doctor of the Kenieba health district to maximize our chance to detect leprosy cases. Thus, villages accessible by car or motorbike and having previous history of leprosy in the past 10 years (based on the leprosy case records available at the CSRéf) were selected.

Source: Filariasis Unit, Faculty of Medicine of Bamako, Mali, 2013.

\section{Study participants' selection and clinical examination}

During the study, all consenting persons living in one of the selected villages were clinically examined for leprosy signs. This work was done house by house by local health care workers (HCWs) previously trained by the research team' leprologist in recognizing the disease clinical signs. This strategy was used to detect all the leprosy cases even those with atypical clinical presentation. Each suspected leprosy case by a HCW was seen by the leprologist to ensure the diagnosis. HCWs were locally hired to strengthen their capacity in diagnosing leprosy and because of their familiarity with the villagers in order to enhance their adhesion to the study.

\section{Data collection tools and procedure}

A census was performed in all the selected villages. A questionnaire focusing on demographics, clinical and biological information was administered to the villagers presenting any dermatological lesion.

All new leprosy cases detected underwent skin biopsy at 2-3 sites as well as dermal juice sampling for histopathological and bacteriological analyses. The biopsies were fixed in a solution of formol and stained with Ziehl-Neelsen stain as previously described [12].

\section{Data analysis}

Data were double-entered into Microsoft office Access 2007 software, and quality control was performed before analysis using SPSS version 20 (Statistical Package for Social Sciences, SPSS Inc., Chicago, IL) and Epi info 2000 (Center for Disease Control and Prevention Atlanta, Georgia, USA).

To estimate the disease prevalence in Kenieba in 2013, the number of leprosy cases under MDT in the CSRéf's leprosy register was added to that detected during the current study. 
To measure the strength of the association between some potential risk factors and the new leprosy cases, we performed a simple logistic regression. A $p$ - value less than 0.05 was considered as significant for all statistical tests.

\section{Ethical aspects}

The study protocol was approved by the National Ethics Committee for Health and Life Sciences of Mali (Acceptance letter number 007/MS-SG-CNESS/2011 du 16 mars/2011). The participation to the present study was on voluntary basis. A collective oral informed consent was obtained from the elders in each study villages. All study participants who underwent a biopsy or dermal juice sampling signed an individual written informed consent.

\section{Results}

\section{Study population characteristics}

A total of 8,457 participants were included in this survey. The median age was 14 years varying from 0 to 102 years. The sex ratio was equal to 0.92 . A proportion of $73.9 \%$ $(6,246 / 8,457)$ of study participants were illiterate and 84 $\%(7,104 / 8,457)$ lived in a rural area. The median number of persons living in the surveyed households was 8 varying from 2 to 63 (Table 1). A number of 353 study participants presented dermatological lesions (Table 4).

\section{Leprosy endemicity and its determinants}

Nine new leprosy cases corresponding to a new case detection rate of 10.64 per 10,000 population were diagnosed during this study (Table 2). They were from the health areas of Dombia (3 cases), Sekotoba (4 cases) and Guénegoré (2 cases) (Table 2). Four of them were multibacillary leprosy and three were found positive to acid-fast bacilli.

The estimated leprosy prevalence was 24.83 per 10,000 population. Kenieba city was the less prevalent health area $(5.56$ per 10,000$)$ in comparison to Guénegoré, the most one (41.57 per 10,000$)$ (Table 3$)$.

Living in Kenieba city $(\mathrm{RR}=0.97, \mathrm{CI}=[0.95-0.99])$, using a bicycle ( $\mathrm{RR}=0.96, \mathrm{CI}=[0.93-0.99])$ or other vehicle as transportation mean to reach the health center $(\mathrm{RR}=0.96, \mathrm{CI}$ $=[0.93-0.99])$ were protective factors significantly associated with new leprosy cases (Table 4). Other factors such as age, education status, gender, time to reach a health center were not associated with leprosy cases (Table 4).

\begin{tabular}{|c|c|c|c|}
\hline $\begin{array}{l}\text { Health } \\
\text { area }\end{array}$ & $\begin{array}{l}\text { Number of new } \\
\text { leprosy cases }\end{array}$ & $\begin{array}{c}\text { Population } \\
\text { clinically examined }\end{array}$ & $\begin{array}{c}\text { New case detection rate (per } \\
10,000 \text { population) }\end{array}$ \\
\hline Dombia & 3 & 1,595 & 18.81 \\
\hline Sekotoba & 4 & 2,461 & 16.25 \\
\hline Guénegoré & 2 & 2,165 & 9.24 \\
\hline Dabia & 0 & 439 & 0 \\
\hline $\begin{array}{l}\text { Kenieba } \\
\text { city }\end{array}$ & 0 & 1,797 & 0 \\
\hline Total & 9 & 8,457 & 10.64 \\
\hline
\end{tabular}

Table 3: variation of leprosy prevalence per health area in Kenieba health district in 2013.

\begin{tabular}{|c|c|c|c|}
\hline Health areas & $\begin{array}{c}\text { Population } \\
\text { examined }\end{array}$ & Leprosy cases* & $\begin{array}{c}\text { Prevalence (per 10,000 } \\
\text { population) }\end{array}$ \\
\hline Guénegoré & 2,165 & 9 & 41.57 \\
\hline Dombia & 1,595 & 4 & 25.08 \\
\hline Sekotoba & 2,461 & 6 & 24.38 \\
\hline Dabia & 439 & 1 & 22.78 \\
\hline Kenieba city & 1,797 & 1 & 5.56 \\
\hline Total & 8,457 & 21 & 24.83 \\
\hline
\end{tabular}

*: Determined by making the sum of the new leprosy cases detected by the research team and the ones documented as being under MDT at the CSRéf level during the study period.

Table 4: Factors associated with the new leprosy cases for simple logistic regression.

\begin{tabular}{|c|c|c|c|c|}
\hline \multirow{2}{*}{ Variables } & \multirow{2}{*}{$\begin{array}{l}\text { Number of persons with } \\
\text { dermatological lesions }\end{array}$} & \multicolumn{3}{|c|}{ New leprosy cases } \\
\hline & & $n$ & Risk ratio & $95 \% \mathrm{Cl}$ \\
\hline \multicolumn{5}{|l|}{ Age groups } \\
\hline$\geq 17$ years & 220 & 7 & 1 & \\
\hline $0-16$ years & 133 & 2 & 0,98 & $0,95-1,01$ \\
\hline \multicolumn{5}{|l|}{ Sex } \\
\hline Male & 188 & 7 & 1 & \\
\hline Female & 165 & 2 & 1,02 & $0,99-1,06$ \\
\hline \multicolumn{5}{|l|}{ Education level } \\
\hline Uneducated & 302 & 8 & 1 & \\
\hline Educated & 51 & 1 & 0,99 & $0,95-1,03$ \\
\hline \multicolumn{5}{|l|}{ Area of residence } \\
\hline Rural & 348 & 9 & 1 & \\
\hline Urban & 5 & 0 & 0,97 & $0,95-0,99$ \\
\hline \multicolumn{5}{|c|}{$\begin{array}{l}\text { Average time spent to } \\
\text { reach the health center }\end{array}$} \\
\hline > 30 minutes & 128 & 3 & 1 & \\
\hline$\leq 30$ minutes & 145 & 6 & 1,01 & $0,97-1,06$ \\
\hline \multicolumn{5}{|c|}{$\begin{array}{l}\text { Mean of transportation } \\
\text { used to reach a health } \\
\text { center }\end{array}$} \\
\hline On foot & 173 & 7 & 1 & \\
\hline By bicycle & 23 & 0 & 0,96 & $0,93-0,99$ \\
\hline By motorcycle & 155 & 2 & 0,97 & $0,94-1$ \\
\hline By other vehicle & 2 & 0 & 0,96 & $0,93-0,99$ \\
\hline
\end{tabular}

Table 1: Study population characteristics.

\begin{tabular}{|c|c|c|c|c|c|c|c|c|c|c|c|c|}
\hline \multirow{3}{*}{ Characteristics } & \multicolumn{10}{|c|}{ Health areas of Kenieba health district } & \multirow{2}{*}{\multicolumn{2}{|c|}{ Total }} \\
\hline & \multicolumn{2}{|l|}{ Kenieba city } & \multicolumn{2}{|c|}{ Guénegoré } & \multicolumn{2}{|c|}{ Dombia } & \multicolumn{2}{|c|}{ Sekotoba } & \multicolumn{2}{|c|}{ Dabia } & & \\
\hline & $n$ & $\%$ & $n$ & $\%$ & $n$ & $\%$ & $n$ & $\%$ & $n$ & $\%$ & $n$ & $\%$ \\
\hline Median age of participants in years (min-max) & \multicolumn{2}{|l|}{$13(0-100)$} & \multicolumn{2}{|c|}{$15(0-89)$} & \multicolumn{2}{|c|}{$14(0-102)$} & \multicolumn{2}{|c|}{$14(0-89)$} & \multicolumn{2}{|c|}{$11(0-95)$} & \multicolumn{2}{|c|}{$14(0-102)$} \\
\hline Median number of persons in a household (min-max) & \multicolumn{2}{|l|}{$7(2-13)$} & \multicolumn{2}{|c|}{$8(2-45)$} & \multicolumn{2}{|c|}{$7(2-63)$} & \multicolumn{2}{|c|}{$7(2-44)$} & \multicolumn{2}{|c|}{$7(2-40)$} & \multicolumn{2}{|c|}{$8(2-63)$} \\
\hline Sex & & & & & & & & & & & & \\
\hline Male & 795 & 44.2 & 1,098 & 50.7 & 802 & 50.3 & 1,158 & 47.1 & 197 & 44.9 & 4,050 & 47.9 \\
\hline Female & 1,002 & 55.8 & 1,067 & 49.3 & 793 & 49.7 & 1,303 & 52.9 & 242 & 55.1 & 4,407 & 52.1 \\
\hline \multicolumn{13}{|l|}{ Education level } \\
\hline Uneducated & 827 & 46 & 1,439 & 66.5 & 1,309 & 82.1 & 2,296 & 93.3 & 375 & 85.4 & 6,246 & 73.9 \\
\hline Educated & 970 & 54 & 726 & 33.5 & 286 & 17.9 & 165 & 6,7 & 64 & 14.6 & 2,211 & 26.1 \\
\hline
\end{tabular}

$n=$ number of subjects; $\min =$ minimum; $\max =$ maximum 


\section{Local health workers' knowledge about leprosy}

Nine health workers in the 5 health areas were questioned on leprosy clinical signs and its treatment to gauge their knowledge about the disease. Six of them knew at least two clinical signs of leprosy, three, its therapeutic regimens and three claimed to have previously being trained in diagnosing the disease.

\section{Discussion}

Four study participants out of the 9 diagnosed of leprosy had the multibacillary form of the disease. This form has a high contamination potential making the condition a serious public health concern at both district and entire country levels as infected people could move from place to place everywhere in the country. The management of these multibacillary forms required an immediate treatment and a close follow-up of the disease evolution.

The current study allowed the detection of 9 new leprosy cases. In 2012, Ivory Coast, India, Nepal, Nigeria, Philippines, Tanzania, South Sudan and Sri Lanka reported new leprosy cases [7]. In India, some areas with leprosy prevalence less than 1 case per 10,000 population still harbor undiagnosed active leprosy cases [13]. The high leprosy new case detection rate reported during our study could be explained by the research method we used. Traditionally, leprosy cases are detected at health centers during routine clinical examination (passive detection). During our study, the health workers actively searched leprosy cases in the visited villages (active detection). This method should be recommended for leprosy cases detection in Mali, especially in the health districts of Kenieba and Douentza, the two with a prevalence still above 1 case per 10,000 population. It will allow the detection of all hidden leprosy cases and contribute to leprosy elimination in these still endemic areas. In 2014, Smith \& Aerts reported that the elimination of leprosy transmission relies on the following elements: early diagnosis and treatment, finding of subjects who have been in contact with the leprosy cases and initiation of post exposure prophylaxis and implementation of a strict epidemiological surveillance [14]. During our study, all new leprosy cases were detected by the undertaken active research method which allowed their early diagnosis and treatment reducing therefore their contamination potential and preventing their mutilating cutaneous and neurological sequelae.

The prevalence of leprosy in Kenieba health district in 2013 was 24.83 cases per 10,000 population. This is more than 20 times higher than that observed in 2012 in this district (Unpublished data). During the past 8 years before the study initiation, about 220,000-250,000 persons have been annually diagnosed with leprosy worldwide [14].

The study questionnaire was administered to anyone with a dermatological lesion except in the villages of Liguiri and Diakoly in Sekotoba health area. In these two villages, the entire population was suffering from an epidemic of scabies. The symptoms of scabies infestations can mimic other dermatological skin diseases like leprosy [15]; additionally, crusted scabies have been in former leprosy patients. Moreover, scabies is very contagious and traditional tests to diagnose scabies are less than $50 \%$ accurate [16]. The local health authorities were informed of this situation for urgent control measures.

The health workers in Kenieba health district had a quite low knowledge level regarding leprosy. This could be explained by their erratic movement between health structures, the rarity of leprosy training and the lack of official updated information about leprosy nationwide. In India, Grewal, et al. in 2013 also observed a low knowledge level of health workers about leprosy [17]. In Mali, Faye, et al. trained 389 community health workers on how to diagnose leprosy. Twelve to 18 months later, they noticed a significant improvement in the trainees' ability to diagnose the disease [18]. Such intervention should be encouraged in endemic and at risk districts in Mali.

We found that all the 9 new leprosy cases were from rural areas. Effective leprosy control must incorporate improvement in the living conditions in endemic communities. In 2014, Freitas, et al. in Brasilia [19] and Entezarmahdi, et al. in Iran [20] reported that leprosy control requires an improvement of socio-economic conditions of people living in endemic areas. In Kenieba health district, this is supported by our findings stating that using a mean of transportation to reach health centers and living in an urban area were protective factors associated with leprosy cases. Indeed, when people are very poor, they cannot afford even the transportation fees to go to the nearest health center and pay for the medical examination fees. Alternative measures to encourage people to seek care for any dermatological lesion that looks like leprosy should be initiated.

In Mali, despite the elimination of leprosy as a public health problem at the country scale, the infection remains highly endemic in Kenieba health district with a prevalence and a new case detection rate respectively of 24.83 and 10.64 per 10,000 population. The challenge is:

First, efforts should focus on information, sensitization of the local population and active campaigns for leprosy detection in endemic communities. Second, health workers should be further trained to diagnose leprosy in order to achieve its elimination goal.

\section{Acknowledgement}

We would like to thank all the study participants, the administrative and health authorities in Kenieba health district, the community health workers and the villagers for their cooperation. A special thanks to the Malian Government 
and the Centre National d'Appui à la lutte contre la Maladie that founded this study through the Malian Government competitive research funds of 2013.

\section{References}

1. World Health Organization (WHO). Working to overcome the global impact of neglected tropical diseases. Geneva: World Health Organization. 2010.

2. Hotez PJ, Molyneux DH, Fenwick A, Kumaresan J, Sachs SE, et al. Contro of neglected tropical diseases. N Engl J Med. 2007; 357: 1018-1027. PubMed: https://www.ncbi.nlm.nih.gov/pubmed/17804846

3. Monot M, Honoré N, Garnier T, Araoz R, Coppée JY, et al. On the origin of leprosy. Science. 2005; 308: 1040-1042.

PubMed: https://www.ncbi.nlm.nih.gov/pubmed/15894530

4. Murto C, Chammartin F, Schwarz K, da Costa LM, Kaplan C, et al Patterns of migration and risks associated with leprosy among migrants in Maranhão, Brazil. PLoS Negl Trop Dis. 2013; 7: e2422. PubMed: https://www.ncbi.nlm.nih.gov/pubmed/24040433

5. Martinez TS, Figueira MM, Costa AV, Gonc, alves MA, Goulart LR, et al. Oral mucosa as a source of Mycobacterium leprae infection and transmission, and implications of bacterial DNA detection and the immunological status. Clin Microbiol Infect. 2011; 11: 1653-1658. PubMed: https://www.ncbi.nlm.nih.gov/pubmed/21199152

6. Weekly epidemiological record (WER). 30 August $2019,94^{\text {th }}$ year. Nos. 35/36. 2019; 94: 389-412.

7. Weekly epidemiological record (WER). 5 September $2014,89^{\text {th }}$ year. No. 36. 2014; 89: 389-400.

8. Jed A. Diner. Geology and Exploration Potential, Sanoukou Claim 2010; 6 .

9. Direction nationale de la santé du Mali. Annuaire système local d'information sanitaire (SLIS) 2013. 2014.

10. Balique H. L'expérience Malienne de Gestion des Ressources Humaines dans le secteur de la santé et ses perspectives. Rapport. 2004-2010.

11. Dogba M, Fournier P, Berthe-Cisse S. Qualification of staff, organization of services, and management of pregnant women in rural settings: the case of Diema and Kayes districts (Mali). ISRN Obstet Gynecol. 2012; 2012: 649412.

PubMed: https://www.ncbi.nlm.nih.gov/pubmed/22619728

12. Pattyn SR. Minimal requirements for the laboratory diagnosis of leprosy in field conditions. Acta Leprol. 1983; 1: 33-40.

PubMed: https://www.ncbi.nlm.nih.gov/pubmed/6401139

13. Singal A, Sonthalia S. Leprosy in post-elimination era in India: difficult journey ahead. Indian J Dermatol. 2013; 58: 443-446.

PubMed: https://www.ncbi.nlm.nih.gov/pubmed/24249895

14. Smith WC, Aerts A. Role of contact tracing and prevention strategies in the interruption of leprosy transmission. Lepr Rev. 2014; 85: 2-17. PubMed: https://www.ncbi.nlm.nih.gov/pubmed/24974438

15. Appelboom T, Cogan E, Klastersky J. Job of the Bible: leprosy or scabies? Mt Sinai J Med. 2007; 74: 36-39.

PubMed: https://www.ncbi.nlm.nih.gov/pubmed/17516561

16. Walton SF, Currie BJ. Problems in Diagnosing Scabies, a Global Disease in Human and Animal Populations. Clin Microbiol Rev. 2007; 20: 268-279. PubMed: https://www.ncbi.nlm.nih.gov/pubmed/17428886

17. Grewal I, Negi Y, Kishore J, Adhish SV. Knowledge and attitude about leprosy in Delhi in post elimination phase. Indian J Lepr. 2013; 85: 123-127. PubMed: https://www.ncbi.nlm.nih.gov/pubmed/24724234

18. Faye 0 , Hay RJ, Ryan TJ, Keita S, Traoré AK, et al. A public health approach for leprosy detection based on a very short term-training of primary health care workers in basic dermatology. Lepr Rev. 2007; 78: 11-16.

PubMed: https://www.ncbi.nlm.nih.gov/pubmed/17518081

19. Freitas LR, Duarte EC, Garcia LP. Leprosy in Brazil and its association with characteristics of municipalities: ecological study, 2009-2011. Trop Med Int Health. 2014; 19: 1216-1225.

PubMed: https://www.ncbi.nlm.nih.gov/pubmed/25040160

20. Entezarmahdi R, Majdzadeh R, Foroushani AR, Nasehi M, Lameei $A$, et al. Inequality of leprosy disability in iran, clinical or socio-economic inequality: an extended concentration index decomposition approach. Int J Prev Med. 2014; 5: 414-423.

PubMed: https://www.ncbi.nlm.nih.gov/pubmed/24829728 